\title{
Scheffel, M. \& Martinez, M. (2020). Anlatım Teorisine Giriş (Almancadan Çeviren: Arif Ünal). İstanbul: Runik Kitap. 271 sayfa. ISBN: 978-605-06194-6-1
}

\section{Fatih EKICi' ${ }^{10}$}

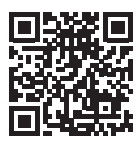

${ }^{1}$ Research Assistant, Faculty of Letters, Department of Contemporary Turkish Dialects and Literatures, Erzurum, Turkey

ORCID: F.E. 0000-0003-4500-9853

\section{Corresponding author:}

Fatih EKICl,

Atatürk Üniversitesi, Edebiyat Fakültesi

Çağdaş Türk Lehçeleri ve Edebiyatları Bölümü, Erzurum, Türkiye

E-mail: fatih.ekici@atauni.edu.tr

Submitted: 19.01 .2021

Accepted: 22.02 .2021

Citation: Ekici, F. (2021). Anlatım Teorisine Giriş [Mihael Scheffel ve Matias Martinez, tarafından yayına hazırlanan Anlatım Teorisine Giriş başlıklı kitabın değerlendirmesi]. Litera, 31(1), 465-471.

https://doi.org/10.26650/LITERA2020-864715

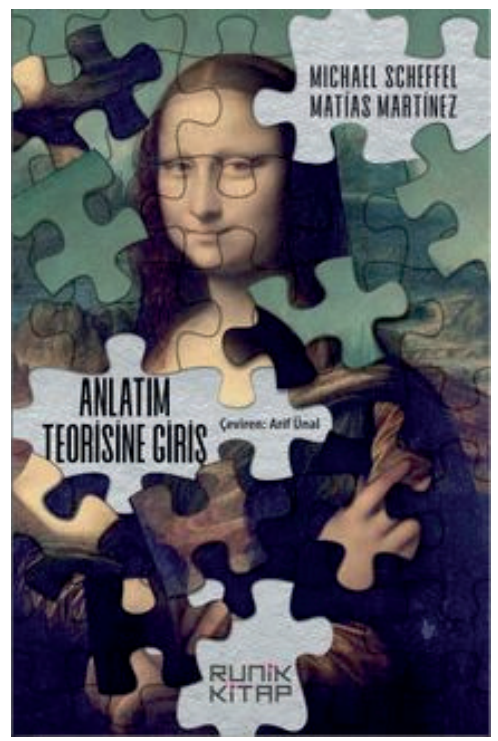

1960'I yıllardan itibaren bir disiplin hâline gelmeye başlayan anlatıbilim, genel bir ifadeyle anlatının bilimsel açıdan incelenmesi olarak tanımlanmaktadır. Disiplin olarak belirmesinin ardından anlatıbilim sahasında Batı'da önemli çalışmalar gerçekleştirilmiş, farklı ekoller gelişim göstermiştir. Türkiye'de ise tam anlamıyla bir anlatıbilim ekolü oluşamamış, -anlatıbilimin oluşumuna önemli katkıları olan 
yapısalcılar ile göstergebilimcilerin çalışmalarından yapılan muhtelif çeviriler ve onlardan esinlenerek ortaya koyulan telif eserler hariç tutulacak olursa- bu sahada yapılan çalışmalar birkaç telif eser ve çeviri kitaptan ibaret kalmıştır'. Buna rağmen son yıllarda ülkemizde anlatıbilim alanında kuramsal manada olmasa da inceleme türündeki yayınlarda bir artış olduğu göze çarpmaktadır. Kitap hacmindeki kuramsal çalışmalar ise farklı dillerden yapılan çeviriler yoluyla Türkçeye kazandırılmaya devam etmektedir. Bu çeviri çalışmaların en sonuncusu ise Alman Dili ve Edebiyatı profesörü Arif Ünal tarafından Türkçeye kazandırılan Anlatım Teorisine Giriş (2021) adlı çalışmadır.

Batı'da gelişim gösteren ekoller içerisinde, Alman anlatıbilimi ve anlatıbilimcileri önemli bir yer tutmaktadır. Wuppertal Üniversitesi Alman Dili ve Edebiyatı (Germanistik) Bölümü profesörlerinden Michael Scheffel ve Matias Martinez'e ait orijinal adı Einführung in die Erzähltheorie ve ilk basım yılı 1999 olan çalışma da bu ekol içerisinde hazırlanan eserlerden biridir. Prof. Dr. Arif Ünal tarafından Anlatım Teorisine Giriş adıyla çevrilen ilgili çalışmanın girişinde yer alan Çevirmenin Önsözü'nde (s. 9); söz konusu çevirinin Türkiye'de anlatı teorisi alanında bir ilk olduğundan bahsedilmektedir. Runik Kitap'tan Temmuz 2020'de çıkan çalışma, basıldığı tarih itibarıyla Türkiye'de anlatı teorisi alanında yayımlanan ilk çalışma değildir ancak çevirmen tarafından yine aynı önsözde ifade edildiği üzere söz konusu çalışmanın çevirisi 2007 yılında yapılmış ve 13 yıl boyunca yayımlanamamıştır. Bu durum göz önüne alındığında, bu iddianın o yıl için geçerli olduğunu kabul etmek mümkündür.

Illk baskısı Almanya'nın köklü yayınevlerinden olan C. H. Beck tarafından 1999 yıında yayımlanan çalışmanın, 2019 yılında en son baskı olan 11. baskısı da aynı yayınevi tarafından yayımlanmışı ı². Çalışma aynı zamanda 2006 yılında Japoncaya (Hosei University Press), 2011 yılında ise İspanyolcaya (Las Cuarenta) çevrilmiştir. Ünal tarafından ilk olarak orijinal yayının 2. baskısına ait Türkçe çeviri 2007 yılında tamamlanmış ancak Çevirmenin Önsözü'nde de (s. 9) ifade edildiği üzere yayınevleri tarafından uzun bir süre söz konusu çeviri basılmamışır. 2020 yılında Runik Kitap tarafından basımına karar verilen yayının güncel çevirisi içinse orijinal son baskı (11.

1 Bunlar arasında Bahar Dervişcemaloğlu'nun Anlatıbilime Giriş (2014), Mustafa Zeki Çıraklı́nın Anlatıbilim: Kuramsal Okumalar (2015); Seymour Chatman'ın Öykü ve Söylem: Filmde ve Kurmacada Anlatı Yapısı (2009) (Ö. Yaren, çev.) ve Manfred Jahn'ın Anlatıbilim: Anlatı Teorisi El Kitabı (2012) (Çev. B. Dervişcemaloğlu) kitapları, genel anlatıbilimle ilgili başıca Türkçe kaynaklar olarak sayılabilir. Anlatıbilimin alt dalı olan söylem anlatıbilimi ve öykü gibi bir tür özelinde yakın zaman önce Oktay Yivli tarafından yayınlanmış Öykü Nasıl Okunur: Modern Öykü ve Yöntem (2019) adlı çalışma da bu bağlamda ele alınabilecek bir örnektir.

2 Aynı yayınevinden çıkan aradaki diğer baskıların yılları sırasıyla şöyledir: 2000, 2002, 2003, 2004, 2005, 2007, 2009, 2012, 2016. 
baskı) baz alınarak gerekli güncelleme ve eklemeler mevcut çeviriye aktarılmıştır. Geçen süre içerisinde orijinal yayının gerek Almanya'da çok sayıda yeni baskı yapmış olması gerekse farklı dillere çevrilmiş olması, anlatıbilim alanında kayda değer bir çalışma olduğuna delil olarak değerlendirilebilir.

Scheffel ve Martinez'in çalışması dört temel bölümden oluşmaktadır. Bunlar; I. Kurmaca Anlatımın Özellikleri, II. "Nası"ın Tasviri, III. "Ne": Olay ve Anlatılan Dünya, IV. Alan Dışı Bakış: Edebiyatbilimi Dışında Anlatım Teorisi Olay Modelleri başıklarını taşımaktadır. Bunlara ek olarak ise çalışmanın sonunda Anlatımbilimiyle Illgili Web Siteleri ile anlatıbilim terimlerinin izah edildiği Kavramlar Sözlüğü başlıkları yer almaktadır. Zengin bir kaynakçaya sahip olan çalışmanın sonunda ise kuramcı ve yazar isimlerinin yer aldığı Dizin bölümü bulunmaktadır.

Birinci bölüm olan Kurmaca Anlatımın Özellikleri başlığı altında öncelikle kurmaca anlatının tanımı ve özellikleri verilmektedir. Bu bağlamda bölümün Gerçekçi ve Kurmaca Anlatım adlı alt başlığı içerisinde gerçek ve kurmaca anlatılara ait tanımlar ve bu ikisi arasındaki farklara ait yorumlamalar yer almaktadır. Kurmaca bir anlatıya ait özellikler ile onun yorumlanmasını kolaylaştıracak metin özellikleri yine bu başlık altında irdelenenler arasındadır. Anlatım ve Anlatılan adlı ikinci alt başlık içerisinde ise bir anlatıya ait iki temel yapı olan söylem ve öykü boyutları "anlatım" ve "anlatılan" terimleri ile ele alınmaktadır. Rus Biçimcilerden başlanarak (Tomaşevski) Yapısalcılara (Todorov) ve anlatıbilimde görüşleri kabul edilen isimlere (Genette vb.) atıfta bulunarak anlatının temel yapısı tartışımakta ve farklı tasnif biçimleri değerlendirilmektedir. Öne sürülen bu farkıııkların içerdiği kavramsal ve terminolojik karışıkığın açık bir şekilde gözden geçirilebilmesi için bölüm sonunda 19 farklı kişinin anlatı yapısına ait tasnifi ve terminolojisi toplu olarak sunulmaktadır. Scheffel ve Martinez, anlatı yapısına ait kendi tasniflerini ise "vaka, olay, hikâye, olay şeması, eser/anlatı ve anlatım" terimleriyle altı ayrı parçada değerlendirmektedirler. Bunlardan ilk dördü anlatının öykü boyutu ile ilgiliyken son ikisi ise söylem boyutuna ait unsurlar olarak kabul edilmektedir.

"Nasıl"ın Tasviri başıิıklı ikinci bölümde anlatının söylem boyutu Zaman, Anlatım Biçimi (Modus), Anlatıcı, Franz K. Stanzel'in "Anlatım Durumları" Tipolojisi ve Güvenilirliği Olmayan Anlatım alt başlıkları ile ele alınmaktadır. İlgili bölümün girişinde Queneau'nun Stilübungen (Üslup Araştırmaları) adlı eserinden tek bir öykünün çeşitli anlatım şekilleriyle oluşturulmuş farklı örnekleri verilmektedir. Bu örneklere ise alt başlıklar altında, kuramsal meseleler anlatılırken sıkça atıfta bulunulmaktadır. 
Anlatıdaki "nasıl"ın yani söylem boyutunun tasvirinden bahisle ikinci başlıkta yer alan ilk alt başlığı Zaman oluşturmaktadır. Yazarlar, burada Günther Müller'i takip ettiklerini belirterek zaman olgusunu "anlatılan zaman" ve "anlatım zamanı" şeklinde iki ayrı kavramla ele almaktadır. Eserde geçtiği şekilde, anlatım zamanıyla "bir anlatııının hikâyesinin anlatımı için gerekli olan ve anlatımın süresi hakkında somut bir bilgi içermeyen bir anlatım metninde basitçe sayfa kapsamıyla ölçülen zaman" (s. 39) ifade edilirken anlatılan zaman kavramıyla ise anlatının "ne"sini oluşturan öykünün süresi kastedilmektedir. Zaman meselesi bu ikili ayrım arasındaki ilişki dikkate alınarak Genette'in geliştirdiği üç kategori altında şu sorulara cevap vermek suretiyle tasnife tabi tutulmaktadır: "Hangi sıraya göre?" (a. Düzen), “Ne kadar süreyle?” (b. Süre) ve "Ne kadar sıklıkla?" (c. Frekans).

Bir anlatıdaki söylem boyutunun önemli birimlerinden biri de anlatıda kullanılan ifade biçimleridir. Anlatım Biçimi (Modus) başsığı altında verilen ifade tarzları benzer çalışmalardan farklı olarak "mesafe" ve "fokalisierung" alt başlıkları ile değerlendirilmektedir. Mesafe kavramıyla öykünün aktarım tarzları üzerinde durulmakta, "olaylar" ve "düşünceler"in aktarımı ayrıca ele alınarak anlatımın dolaylı ya da doğrudan olması kriteri esasında kullanılan ifade biçimleri/anlatım teknikleri açıklanmaktadır. Türkçeye çevrilmeden "fokalisierung" şeklinde verilen "bakış açısı", "odaklanma" vb. şeklinde çevirebileceğimiz ikinci kavramla ise öykünün aktarımında yalnızca mesafenin belirleyiciliğinden değil, aynı zamanda farklı bakış açılarından da faydalanılabileceği belirtilmektedir. Burada Genette'in meseleye ilişkin görüşleri geliştirilerek sunulmakta ve özgün örneklerle desteklenmektedir.

Anlatının "nasıl"ının en önemli, hatta kurucu unsuru olarak kabul edilen anlatıcı kategorisi de anlatıma ait üçüncü alt başlıkta ele alınmaktadır. Burada anlatma eyleminin ve anlatıcı kimliğinin yanında, anlatıcının anlatılan öykü ve anlatma eyleminin muhatabı okuyucu ile olan ilişkisi meseleleri de değerlendirilmektedir. Anlatıcıyı daha iyi analiz edip ortaya çıkarabilmek için ona dair bu meseleler; anlatıya ait anlatım zamanının tespitini amaçlayan "Anlatma Zamanı", anlatıcının anlatı içerisindeki düzeyini tespit edebilmek için "Anlatımın Yeri", anlatıcının anlatılan öyküde yer alıp almama durumuna göre "Anlatııının Olaya Tavrı" ve anlatıcı kimliğiyle birlikte muhatabının da kim olduğunun tespit edilmesini mümkün kılan yöntemleri içeren "Anlatıcının Kimliği ve Muhatabı" başlıkları altında incelenmektedir. 
"Franz K. Stanzel'in 'Anlatım Durumları' Tipolojisi" başığını taşıyan, söylem boyutunun altında yer alan dördüncü başlıkta ise anlatıdaki anlatma eyleminin tüm çeşitlerini tipolojik bir tasnifle ele alan araştırmacı Stanzel'in görüşlerine yer verilmekte, onun bu tasnifi kitabın yazarları Scheffel ve Martinez tarafından geliştirilen anlatım modelleriyle karşılaştırılarak eleştirilmektedir. Kitabın ikinci bölümünün son alt başlığı olan beşinci başlık ise "Güvenilirliği Olmayan Anlatım" adını taşımaktadır. Burada kurmaca anlatının kendi gerçekliği içinde ele alındığında, taşıdığı söyleme ait ifadelerin bu gerçekliği ne ölçüde koruduğu irdelenmekte ve farklı kıstaslarla bunların seviyelerine göre anlatıya dair bir güvenilirlik/tutarlılık tahlili yapma yöntemi sunulmaktadır.

“'”Ne": Olay ve Anlatılan Dünya" başlıklı üçüncü ana bölümde anlatının "ne"sini, yani içeriğini oluşturan öykü; dört alt başlık altında farklı açılardan ele alınmaktadır. Bunlardan ilki olan "Olayın Unsurları" alt başlığında Rus Biçimcilerden hareketle anlatının "ne"sine ait en küçük birimin vaka olduğuna değinilerek Forster vb. isimlerin yaklaşımıyla bu vakaların arka arkaya birbirlerini takip etmesiyle olayın, bir kurala uygun olarak birbirinden bağımsız sıralanmasıyla ise öykünün meydana çıktığı vurgulanmaktadır. Olay ve öykü arasındaki fark ise (1) nedene yönelik motivasyon, (2) amaca yönelik motivasyon ve (3) estetik motivasyon şeklinde üç farklı yaklaşımla değerlendirilmektedir. Yine öykünün karmaşık yapısını anlaşılır kılmak için faydalanılması gereken olay şeması da burada ele alınanlar arasındadır.

Kendi dünyasını tasarlayan kurmaca metinlerin ortaya koyduğu bu dünyalar, "Anlatılan Dünyalar" adıyla anlatının "ne"sine ait ikinci alt başlıkta ele alınmaktadır. Bir bütünlük oluşturması beklenen bu kurgusal dünyalara ait karşıtıklar dört ayrı kategoriye ayrılarak burada değerlendirilmektedir: (1) Homojen ve Heterojen Dünyaların Karşıtlığı, (2) Tek Bölgeli ve Çok Bölgeli Dünyaların Karşıtlığı, (3) Değişmez, İstikrarlı Dünya ile Değişken ve İstikrarsız Dünyanın Karşıtlığı, (4) Mümkün Olanla Mümkün Olmayan Dünyaların Karşıtığı.

Kurmaca dünyanın sakinlerini "insanlar" ve "şahıslar" kavramlarından farklı olarak ve bu farkı ortaya koymak amacıyla "figürler" olarak adlandıran Scheffel ve Martinez, "Figür" başlığı altında bu meseleye yer vermektedirler. Kurmaca anlatılar ile gerçek anlatıların sahip olduğu bu figürler arasındaki farklara vurgu yapılmakta, kurmaca anlatının figürlerine ait özellikler aktarılmaktadır. Ardından anlatılan dünyanın herhangi bir figürü hakkında metinde verilen tüm bilgilerin "Figür Karakter Analizi" 
yöntemiyle toplanabileceğinden bahisle -örneklerle de destekleyerek- kısaca bu yöntem üzerinde durulmaktadır.

Olay, zaman ve figürlerle birlikte anlatılan dünyanın önemli yapısal parçalarından biri olan "Mekân", anlatının içeriğine ait bölümün son alt başlı̆̆ını oluşturmaktadır. Burada metinlerde yer alan kurmaca mekânlar, "diegetik mekân" terimiyle ele alınıp onlara ait özellikler verilmektedir. Sonrasında ise kurmaca mekânların oluşturulmasında ve analizinde Juri Lotman'ın konu teorisi (Sujettheorie)nin etkisinden söz edilerek bu teoriye ait bilgiler aktarılmakta ve örnekler üzerinden açıklanmaktadır.

Rus Biçimciler, yapısalcılar ve göstergebilimcilerin edebî metine yaklaşımlarındaki tecrübelerden faydalanarak 1960'lı yıllardan itibaren bir disiplin hâline gelmeye başlayan anlatıbilim, genellikle iki dönem şeklinde ele alınmaktadır. Yalnızca edebî anlatılarla ilgilenen ve bunu metnin dışına çıkmadan, anlatı metnini esas malzeme olarak kabul ederek gerçekleştiren ilk dönem, klasik anlatıbilim ya da yapısal anlatıbilim adlarıyla anılmaktadır. Özellikle 1990'ı yıllardan itibaren anlatıbilimin yalnızca edebî anlatılar ve metin içi unsurlara olan ilgisinin yanında, anlatı metinlerinin oluşmasında etkili olan metin dışı etkilere de yönelmesi söz konusu olmuştur. Bununla birlikte disiplinlerarası bir boyut kazanan anlatıbilimin bu dönemi ise klasik sonrası anlatıbilim ya da modern anlatıbilim gibi adlarla anılmaktadır. Anlatıbilimin günümüzde anlatmak eyleminin var olduğu neredeyse tüm disiplinlerle ilişki içerisinde olduğunu söylemek yanlış olmayacaktır. İncelediğimiz Anlatım Teorisine Giriş adlı çalışmanın dördüncü bölümü de bu konuya ayrılmış olup anlatıbilimin sıklıkla etkileşim hâlinde olduğu disiplinlerle olan ilişkisine atıfta bulunmaktadır. "Alan Dışına Bakış: Edebiyatbilimi Dışında Anlatım Teorisi Olay Modelleri" başlığını taşıyan bu bölümde anlatıbilimin edebî anlatım konusu yanında toplumdilbilim, bilişsel psikoloji, antropoloji ve tarih alanlarındaki anlatım teorilerine ve tekniklerine tanıtıcı mahiyette yer verilmektedir.

Çalışmanın esas bölümleri bittikten sonra "Araştırma Literatürü ile Illgili Bilgiler" başlığı altında kitapta yer alan bölüm başlıkları aynen alınarak ve her başlığın altında o konuyla ilgili kaynaklar değerlendirilmek suretiyle detaylı bir literatür taraması sunulmaktadır. Burada yer alan genel anlatıbilim çalışmaları yanında özellikle Almanca literatüre uzak olanlar açııından verilen kaynaklar ve bu kaynaklar hakkında yapılan açıklamalar büyük önem taşımaktadır. Mevcut çevirinin kitaba ait en son 
baskıyı dikkate alarak gerçekleştirilmesi de güncel alan çalışmalarının burada yer almasını mümkün kılması açısından da ayrıca kıymetlidir. Bu bölümün ardından gelen "Anlatımbilimiyle İlgili Web Siteleri" başlığı altında ise Avrupa ve ABD'deki çeşitli anlatıbilim okullarına ait web sitelerinin bilgileri verilmektedir. Burada yer alan bilgiler de son baskıyla birlikte güncellenen bilgiler arasındadır.

Son sayfalarda "Kavramlar Sözlüğü" adı altında eserde geçen anlatıbilimle ilgili terimlere yer verilmektedir. Burada yer alan terimler orijinal şekliyle bırakılarak Almanca terimlerin Türkçe karşılıkları, onların yanında parantez içerisinde bulunmaktadır. Türkçe karşılıklara göre ayrıca alfabetik bir sıralama yer almamaktadır. Büyük bir kısmı literatür ile ilgili bilgilerin yer aldığı bölümde açıklanan kaynakların künye bilgileri ise "Kaynakça" kısmında birincil ve ikincil kaynaklar şeklinde iki ayrı başlık altında sunulmaktadır. Çalışma, en sonda yer alan ve yalnızca kişi isimlerinin yer aldığı “Dizin” bölümüyle ise son bulmaktadır.

Michael Scheffel ve Matias Martinez'e ait Arif Ünal tarafından Türkçeye kazandırılan bu çalışmanın genel bir değerlendirmesini yapmak gerekirse yukarıda bahsedilenler dışında dikkat çeken diğer hususlar şunlardır: Ülkemizde çoğunluk tarafından bilinen genel yabancı dilin İngilizce olması nedeniyle bu dilin dışındaki dillerde yazıımış anlatıbilim kaynaklarının da Türkçeye kazandırılması oldukça önemlidir. Öyle ki incelediğimiz bu çeviri eser, Alman anlatıbilim ekolüne uzak olanlar için yeni kaynaklarla tanışma fırsatını da sunmaktadır. Neredeyse her bölüm içerisinde ve sonunda yer alan şemalar, Alman sistematiği ve araştırma metodolojisi hakkında da bilgiler vermektedir. Çalışmada kullanılan örnek metinlerin eser adları verilirken genellikle orijinallerinin verilmeye çalışıldığı, Türkçeye çevrilmiş olanlarda ise ikisinin birden kullanıldığı görülmektedir. Teorik bilgilere yönelik oldukça zengin örnekler sunması da anlatılan meseleyi daha anlaşıı kılmaktadır. Bu noktada çalışmada verilen bazı yabancı isimler ve terimlerin ise kendi dillerindeki orijinal hâlleri yerine Almanca hâliyle kaldığı (örn. Michail Bachtin vb.) görülmektedir.

\section{Kaynakça}

Scheffel, M. \& Martinez, M. (2020). Anlatım Teorisine Giriş (A. Ünal, Çev.). İstanbul: Runik Kitap. 
